\title{
Local-global strategy for the prediction of residual stresses in FSW processes
}

\author{
N. Dialami, M. Cervera, M. Chiumenti and C. Agelet de Saracibar \\ International Center for Numerical Methods in Engineering (CIMNE), \\ Technical University of Catalonia, Module C1, North Campus \\ C/ Gran Capitán s/n 08034 Barcelona, Spain \\ E-mail addresses: narges@cimne.upc.edu (N. Dialami), \\ michele@cimne.upc.edu (M. Chiumenti), mcervera@cimne.upc.edu (M. Cervera), \\ agelet@cimne.upc.edu (C. Agelet de Saracibar)
}

\begin{abstract}
This work describes the local-global strategy proposed for the computation of residual stresses in Friction Stir Welding (FSW) processes. A coupling strategy between the analysis of the process zone nearby the pin-tool (local level analysis) and the simulation carried out for the entire structure to be welded (global level analysis) is implemented to accurately predict the temperature histories and, thereby, the residual stresses in FSW.

As a first step, the local problem solves the material stirring as well as the heat generation induced by the pin and shoulder rotation at the heat affected zone. The Arbitrary Lagrangian Eulerian (ALE) formulation is adopted to deal with the rotation of complex pin shapes. A thermo-rigid-viscoplastic constitutive law is employed to characterize the viscous flow of the material, driven by the high strain rates induced by the FSW process. A mixed temperaturevelocity-pressure finite element technology is used to deal with the isochoric nature of the the strains. The output of this local analysis is the heat generated either by plastic dissipation or by friction and it is used as the power input for the welding analysis at structural (global) level.
\end{abstract}

The global problem is tackled within the Lagrangian framework together with a thermoelasto-viscoplastic constitutive model. Also in this case the mixed temperature-displacement- 
pressure format is introduced to deal with the deviatoric nature of the plastic strains. The outcomes of this analysis are the distortions and the residual stresses after welding.

The proposed numerical strategy is validated by the experimental evidence.

Key Words: FSW, Local-global analysis, Residual stresses, Coupled thermo-mechanical analysis, Finite element method, ALE framework.
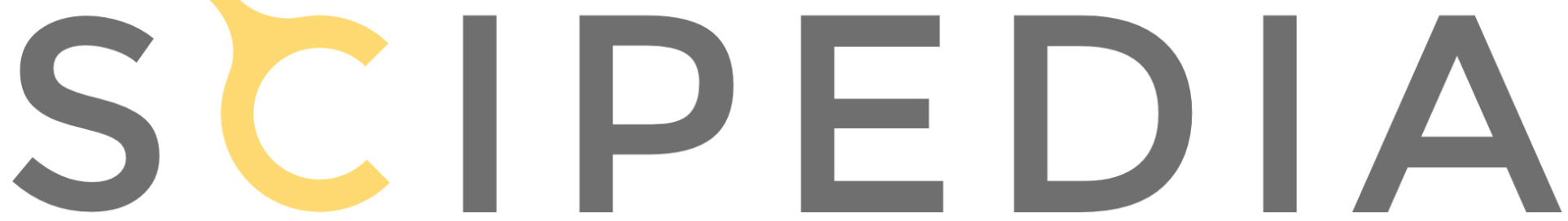

Register for free at https//www.scipedia.com to download the version without the watermark 


\section{Introduction}

Friction stir welding (FSW) is a relatively new solid state welding technique suitable for joining lightweight metal sheets that are difficult to weld otherwise. The process is applicable to aerospace, shipbuilding, aircraft and automotive industries.

During FSW, the work-piece is placed on a backup plate and it is clamped rigidly to eliminate any degrees of freedom. A non-consumable tool, rotating at a constant speed, is inserted into the welding line between two pieces of sheet and generates heat while advancing along the weld path. This heat is produced by the friction between the tool shoulder and the work-pieces and by the mechanical mixing (stirring) process in the solid state. This results in the plastification of the material close to the tool at very high strain rates inducing very high

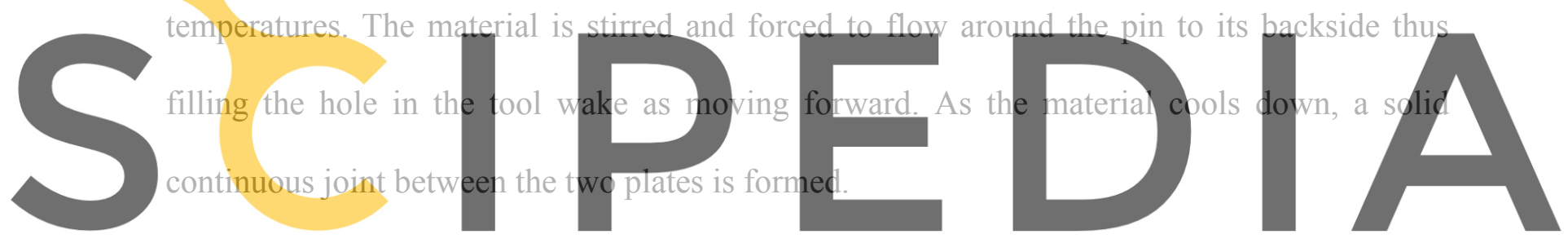

Since FSW occurs by the deformation of material at temperatures below the melting point, Register for free at https//www.scipedia.com to download the version without the watermark many problems commonly associated with fusion welding technologies can be avoided and

high-quality welds are produced.

Generally, FSW yields fine microstructures, absence of cracking, low residual distortion and no loss of alloying elements. Nevertheless, as in the traditional fusion welds, a softened heat affected zone and a tensile residual stress field appear.

Although the residual stresses and distortion are smaller in comparison with those of traditional fusion welding, they cannot be ignored specially when welding thin plates of large size.

Typically, when studying welding processes, there exist two points of view: on one side, at local level, the target is the welding pool, where the heat source is focused or, in the case of 
FSW, where the heat is generated by plastic dissipation and friction. The objective of the study is the material behavior and the microstructure evolution taking place at heat affected zone (HAZ). On the other side, when the entire structure (global level) is analyzed, the target is to consider the effect of welding process in terms of distortions, residual stresses and ultimate strength along the welding line.

The authors developed a numerical strategy to analyse the FSW process at local level. The Arbitrary Lagrangian Eulerian (ALE) formalisms have been proposed to deal with noncylindrical pin-shapes (see references [1-9]). A mixed stabilized sub-grid scale finite technology has been adopted to solve coupled thermo-mechanical problems with a rigidviscoplastic constitutive behaviour [4]. The FE technology was able to deal with the isochoric

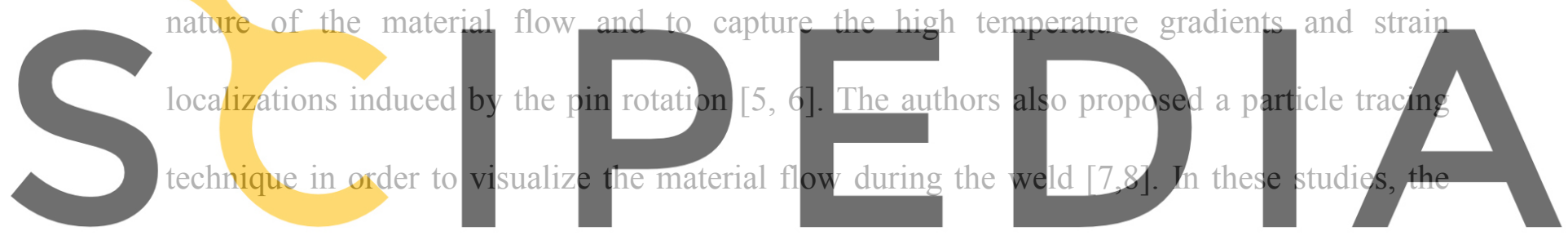

computation of residual stresses was not the objective, as the process zone is extremely small

Register for free at https//www.scipedia.com to download the version without the watermark compared to the size of the structure to be welded, and their effect is negligible. It must be

also noted that, typically, the material stirring at the process zone in FSW analysis is tackled assuming a rigid-visco-plastic material behavior (non-Newtonian viscous laws such as Norton-Hoff, Bingham, Sheppard-Wright, among others) where the elastic strains are neglected in comparison with the plastic flow.

The authors have also carried out different thermo-mechanical analyses such as casting and welding processes from the structural (global) point of view [12-14].

In these cases, the Lagrangian framework is adopted for the analysis of the entire component (structure) and it is coupled with a thermo-elasto-viscoplastic constitutive law covering the entire temperature range from room to (and above) the melting point. The thermal 
expansion/contraction induced by the temperature field as well as both the latent heat release and the shrinkage occurring during the liquid-to-solid phase transformation is taken into account. The distortions and residual stresses produced by the manufacturing process are the principal outcomes of the solution strategy used.

Several authors have presented thermo-mechanical models for the prediction of the distribution of the residual stresses in the process of friction stir welding. Shi et al. [26] presented one single model for the calculation of the residual stresses and compared two cases: one including exclusively the effect of the thermal loads on the residual stresses and another one including both the thermal and the tool load effects. They found a peak value of the longitudinal residual stress of the order of $200 \mathrm{MPa}$ in both cases. The maximum was

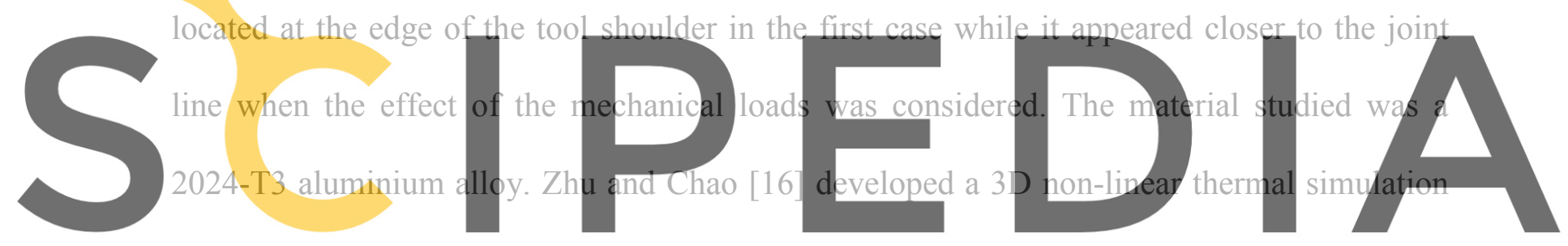

using an inverse FEM analysis on 304L stainless steel plates. Khandkar et al. [17] used a

Register for free at https//www.scipedia.com to download the version without the watermark coupled thermo-mechanical FE model based on torque input for calculating temperature and

residual stresses in aluminium alloys and 304L stainless steel. The thermal analysis was based on analytical models.

Buffa el al. [15] simulated the welding process using a continuous rigid-viscoplastic finite element model in a single block approach through the Lagrangian implicit software, DEFORM-3DTM. Then, the temperature histories extracted at each node of the model were transferred to another finite element model considering elasto-plastic behavior of the material. The map of the residual stress was extrapolated from the numerical model along several directions by considering thermal actions only. A steady-state simulation of FSW was carried out by Bastier et al. [18]. The simulation included two main steps. The first one uses an 
Eulerian description of the thermo-mechanical problem together with a steady-state algorithm detailed in [19], in order to avoid remeshing due to the pin motion. In the second step, a steady-state algorithm based on an elasto-visco-plastic constitutive law was used to estimate the residual state induced by the process. In this approach, the same mesh must be used for both models in order to facilitate variable transferring. This is disadvantageous as it requires using a relatively large mesh in both models. Otherwise, point-to-point temperature transfer methods do not conserve energy because of the extrapolation error committed.

Some other authors used both experimental and numerical methods for computing the residual stresses. McCune et al. [20] studied computationally and experimentally the effect of FSW improvements in terms of panel weight and manufacturing cost on the prediction of residual

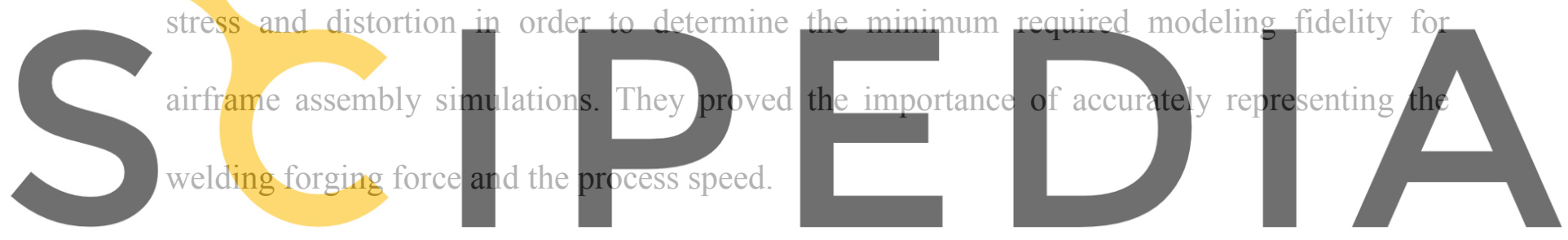

Paulo et al. [21] used a numerical-experimental procedure (contour method) to predict the Register for free at https//www.scipedia.com to download the version without the watermark residual stresses arising from FSW operations on stiffened panels. The contour method

allowed for the evaluation of the normal residual stress distribution on a specimen section. The residual stress distribution was evaluated by means of an elastic finite element model of a cut sample, using the measured and digitalized out-of-plane displacements as input nodal boundary conditions.

Yan et al. [22] adopted a general method with several stiffeners designed on the sheet before welding. Based on the numerical simulation of the process for sheet with stiffeners, the residual distortion of the structure was predicted and the effect of the stiffeners was investigated. They verified first the numerical model experimentally and then applied the verified model on the structure to compute the residual stresses. 
Fratini and Pasta [23] used the cut-compliance and the inverse weight-function methodologies for skin stringer FSW geometries via finite element analysis to measure residual stresses.

Rahmati Darvazi and Iranmanesh [24] presented a thermo-mechanical model to predict the longitudinal residual stress applying a so-called advancing retreating factor. The uncoupled thermo-mechanically equations were solved using ABAQUS.

The objective of the current investigation consists in coupling the local level simulation, used to estimate the heat generated by plastic stirring and friction mechanism, with the global level simulation to predict residual stresses in FSW (see figure 1).

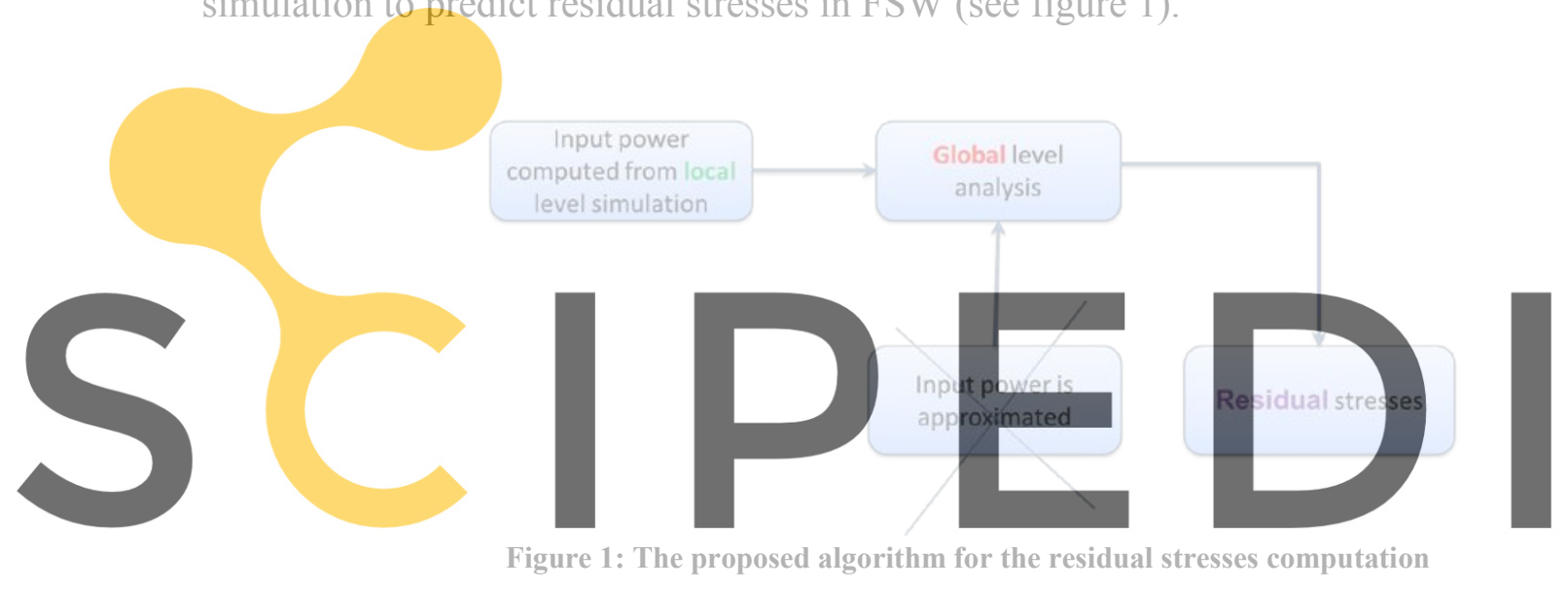

\section{Register for free at https//www.scipedia.com to download the version without the watermark}

The outline of the paper is as follows. First, the solution strategy including both local and

global level models is described (Section 2). Next, the experimental validation of the proposed strategy is presented (Section 3).

\section{Solution strategy}

The straight-forward two-step strategy to compute the residual stresses is to transfer the temperature field obtained at nodes of the local model to the global one $[15,18,19]$. In this case, two possibilities exist. One is to use exactly the same mesh for the local and the global models. This rigid procedure is computationally expensive and ineffective. The other possibility is to transfer the temperature obtained from the local model to a different mesh in the global model. An ideal data transfer method should introduce minimum numerical 
diffusion, conserve the extrema, and be data-consistent. Straight-forward point-to-point transfer of the temperature field, either node-to-node or integration point-to-integration point does not meet these requirements. Alternatively, temperature transfer can be done minimizing the difference of the fields in the two meshes (weak conservation by the Mortar Element Transfer Method [27, 28]). Even though this method minimizes the numerical diffusion, it can introduce oscillations around steep variations of the field.

In this work, a different two-step strategy for computing the residual stresses is based upon combining local and global level analyses. The local model is used to compute the power input for the global model in an energy conserving form. This is explained next and illustrated in figure 2.
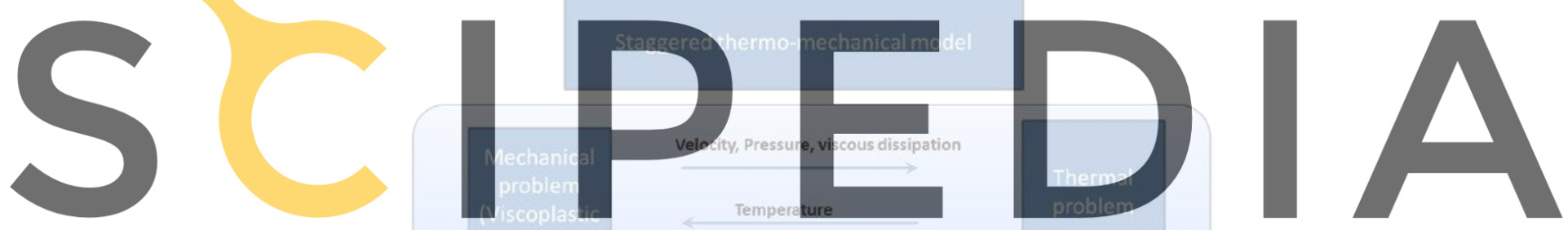

Register for free at https//www.scipedia.com to download the version without the watermark \begin{tabular}{l|l} 
At steady-state & Total power input
\end{tabular}

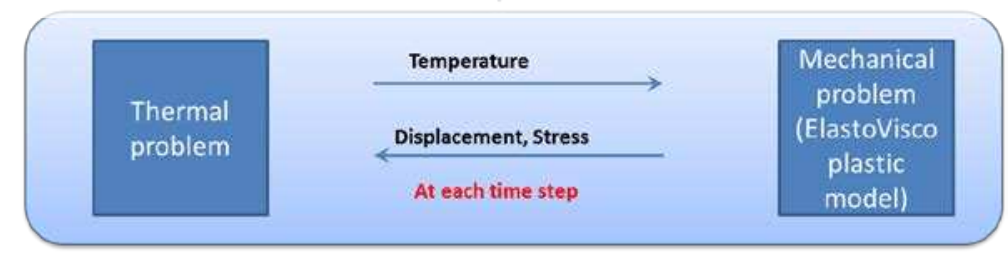

Figure 2: Coupling strategy at local and global level

\subsection{Local level analysis}

The first step consists of computing the heat generated by the FSW tool at the thermomechanically affected zone (TMAZ) and the corresponding temperature field induced. This is performed (only once) by the local level analysis and it is the main input for the global level analysis. The focus of this simulation is not the whole component but, instead, a small domain 
(typically, its size is the double of the pin-shoulder) including the TMAZ (see figure 3). The pin rotation axis is kept fixed in the reference frame while the work-pieces move with the imposed advancing (welding) velocity (relative movement). The transient problem is characterized by a very strong thermo-mechanical coupling, because on one side the heat is generated by the plastic dissipation and friction mechanisms and, on the other side, the material properties (and particularly the flow stress) are strongly temperature dependent.

At local level, the analysis is characterized by the pin geometry, the rotation and the advancing speeds and the thermo-physical properties of the sheet material to be welded. The focus is the relationship between the process parameters and the corresponding heat generation, as well as the feasibility and quality of the final joint [1-11].
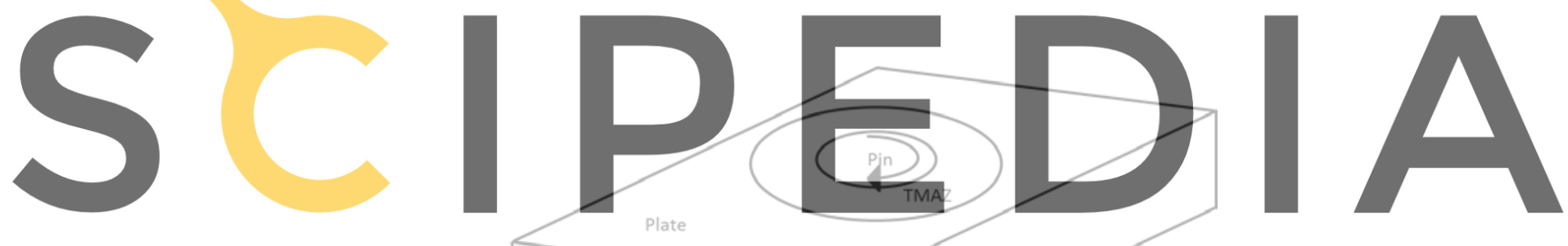

Register for free at https/ywww, scipedia.com to download the Version without the watermark

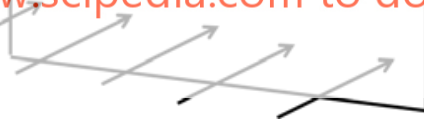

Figure 3: Domain splitting used for the local analysis

The velocity field is the natural choice to deal with the Eulerian or ALE frameworks. Hence, the stresses are defined in terms of the velocities field rather than displacements. Therefore, non-Newtonian laws are most suitable to study a material behaviour which is characterized by very high strain rates as well as a wide temperature range going from the environmental temperature to the one close to the melting point. For this reason, the model is defined in terms of strain rates rather than strains. The elastic strains are neglected compared to the viscoplastic flow and, therefore, precluding the computation of residual stresses. 
Different rate-dependent constitutive models can be used for modelling the FSW process. In the present work, Sheppard-Wright constitutive model is considered ([4-6]). The main common advantage of the this model is the possibility of a better calibration of the material behavior in the entire temperature range from the environment temperature to the melting point as the temperature dependency is explicit in the model.

The FE technology used to solve the local analysis is based on a mixed velocity-pressuretemperature formulation to deal with the isochoric behavior of the material flow ([4-6]). The problem evolves from a specified initial condition, for instance, the room temperature (with or without pre-heated tools and pieces), to a steady-state situation defined by temperature, velocity and stress fields. The coupled thermo-mechanical problem is solved by means of a

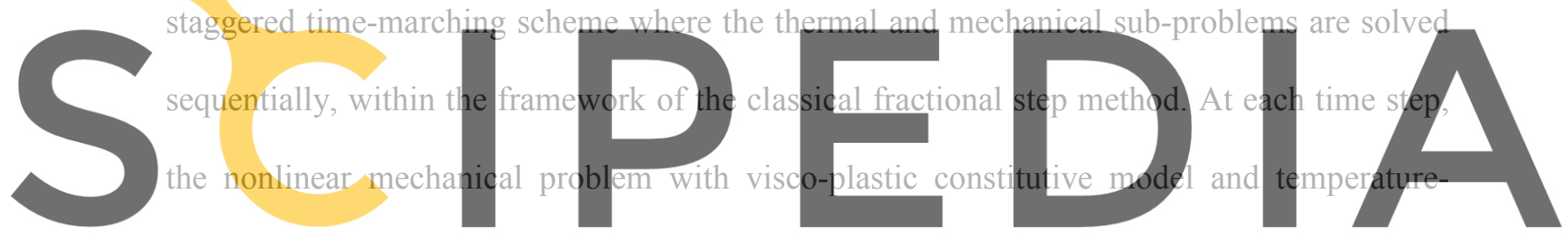

dependent properties is solved first, at constant temperature, until the convergence is Register for free at https//www.scipedia.com to download the version without the watermark achieved. Then, the thermal problem is solved, keeping the mechanical variables (velocity and

pressure) constant (figure 2).

This analysis requires extremely fine mesh in the TMAZ because in this region both temperature gradients and the strain rates are very steep. This localization is mainly due to the highly non-linear behaviour of the constitutive model that characterizes the material.

The output of the local analysis is the heat power to be used as input for structural (global) level simulation. This energy is calculated once the steady-state condition is achieved that is when the equilibrium between the heat generated and the heat loss through the boundaries is established. The main contributions are the heat generated by friction, $q_{\text {frict }}$ at the contact 
interface between the pin and pin-shoulder with the sheet surface, and by plastic dissipation $\dot{D}_{\text {mech }}$ at the TMAZ. Therefore, the heat power $(\dot{P})$ is obtained as;

$$
\dot{P}=\int_{\Omega_{T M A Z}}\left(\dot{D}_{m e c h} \delta T\right) d V+\int_{\partial \Omega_{T M A Z}}\left(q_{\text {frict }} \delta T\right) d S
$$

The proposed strategy is energy conserving (see ref. [25]) provided that: a) the amount of heat generated by friction and plastic dissipation outside the HAZ can be neglected and b) the temperature variation due to heat conduction on the inflow and lateral boundaries of the local model during the welding operation is negligible.

To this end, the definition of the sizes of the local model and the HAZ must be large enough. Being the shoulder diameter $d_{0}$, in this work, the HAZ region has $2 d_{0}$ diameter and the plate is a square of $4 d_{0} \times 4 d_{0}$ (see figure 4 ).

The formulations used for the local problem are summarized in table 1 (see ref. $[5,6]$ and nomenclature at the end of the article).

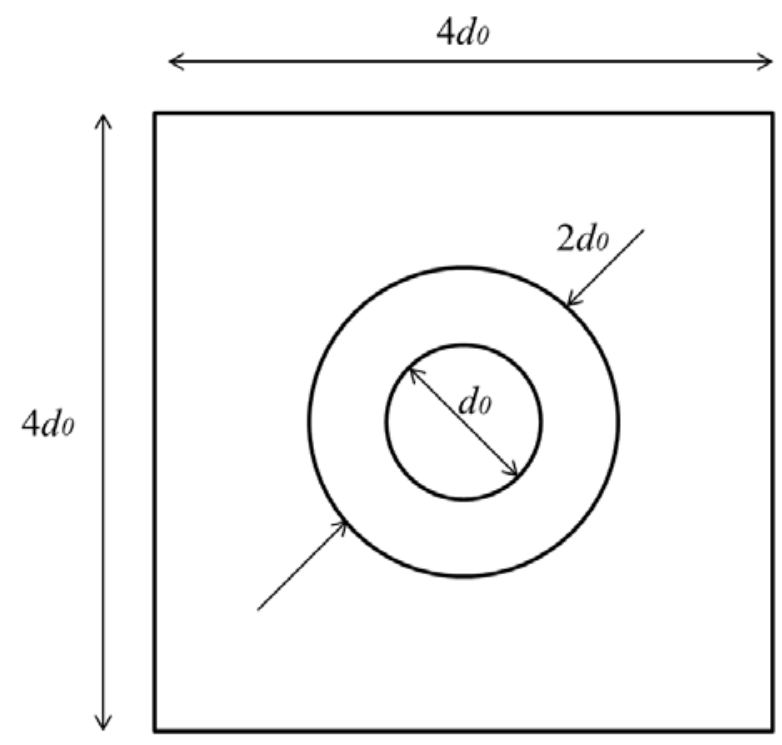

Figure 4: Size definition of the local model 
Table 1: Formulations used at local level

\begin{tabular}{|c|c|}
\hline & Mechanical partition \\
\hline$\nabla \cdot \mathbf{s}+\nabla p+\rho_{o} \mathbf{b}=\mathbf{0}$ & Balance equation \\
$\nabla \cdot \mathbf{v}=0$ & Continuity equation \\
$\boldsymbol{\sigma}=p \mathbf{I}+\mathbf{s}$ & Stress split \\
$\dot{\boldsymbol{\varepsilon}}=\nabla^{s} \mathbf{v}$ & Kinematic equation \\
$\mathbf{s}=2 \mu_{e f f} \dot{\boldsymbol{\varepsilon}}$ & Constitutive equation \\
\hline \multicolumn{2}{|c|}{ Thermal partition } \\
\hline$\rho_{0} c\left(\frac{d T}{d t}+\left(\mathbf{v}-\mathbf{v}_{\text {mesh }}\right) \cdot \nabla T\right)+\nabla \cdot \mathbf{q}=D_{\text {mech }}$ & Energy equation \\
$\mathbf{q}=-k \nabla T$ & Heat flux \\
$D_{\text {mech }}=\beta \mathbf{s}: \dot{\mathbf{e}}$ & Viscoplastic dissipation \\
$q_{\text {conv }}=h\left(T-T_{\text {env }}\right)$ & Heat convection \\
$q_{\text {cond }}=h_{\text {cond }}\left(T-T_{\text {env }}\right)$ & Heat conduction \\
$q_{\text {rad }}=\sigma_{\text {rad }} \varepsilon_{\text {rad }}\left(T^{4}-T_{\text {env }}^{4}\right)$ & Heat radiation \\
\hline
\end{tabular}

\subsection{Global level analysis}

The second step of the simulation strategy consists of performing the analysis of the entire component to be welded (global level analysis). In this case, the Lagrangian framework is preferred. A moving heat source is applied to a control volume representing the position of the actual TMAZ during the welding process (see figure 5). In this work, its actual value is neither approximated nor obtained experimentally. Instead, it is computed in the first step of the proposed numerical strategy.

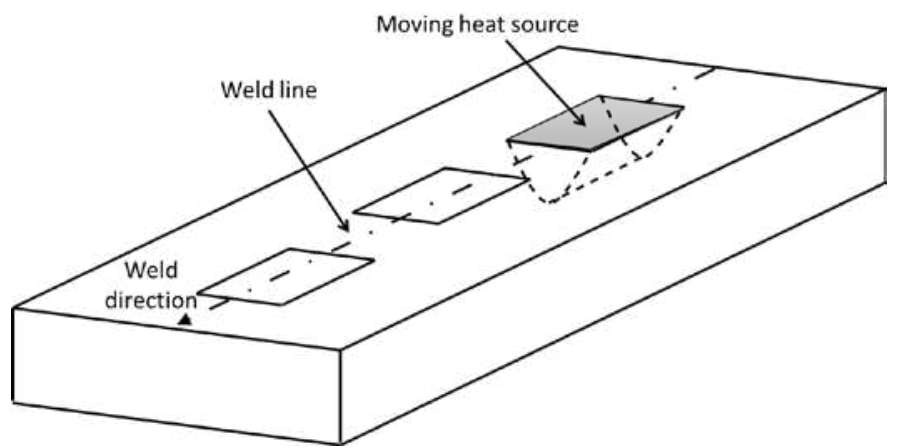

Figure 5: Schematic representation of a global model with a moving heat source 
The distortions and the residual stresses induced by the welding process are the main target of the study. In this case, the structural behaviour is affected by the thermal loading (heat source) and the corresponding heat loss through the boundaries by heat convection and radiation, as well as by the mechanical loading (gravity load and tool pressure) and the mechanical constraining due to the clamping system.

Residual stresses and distortions are induced by the thermal expansion of the material at the process zone. The clamping system prevents this expansion so that the thermal deformations transform into plastic strains and, therefore, producing residual stresses in both longitudinal and transversal directions in the weld and its vicinity.

In global level analysis, the Lagrangian framework is used so that the displacements are the natural choice to solve the mechanical problem. The material behavior is characterized by an elasto-plastic behavior at room temperature which transforms into a pure viscous model when the temperature field is close to the melting point. This evolution can be conveniently defined by a thermo-elasto-visco-plastic constitutive model, which considers a temperature dependent yield surface vanishing at liquidus temperature as presented in [25].

The global analysis is defined by a transient problem where the time-marching scheme is used to compute the evolution of the displacement, pressure and temperature fields, respectively.

Also in this case, the thermo-mechanical coupling is solved by means of a staggered algorithm. At each time step, the mechanical problem is solved first, at constant temperature. Then, the thermal problem is solved at constant configuration (figure 2).

The only data transferred between the two-scale analysis is the heat source, as the size of TMAZ and the corresponding plastic deformations generated by the material stirring are negligible if compared with the dimension of the structural component to be welded. 
The numerical simulation at global level needs an ad-hoc procedure in order to apply the power energy to the elements representing the TMAZ at each time step of the simulation (figure 6). Therefore, a search algorithm is required to identify those elements. The total power input, $\dot{P}$, delivered within the time-step, $\Delta \mathrm{t}$, is uniformly distributed among the elements belonging to the TMAZ volume during the current time-step. The upper surface of this control volume is a rectangle with dimension of advancing speed $(v) \times$ time step $(\Delta t) \times$ pin-shoulder diameter $\left(d_{0}\right)$. The size of the TMAZ $(d)$ decreases parabolically through the thickness $(h)$ of the work-piece (see figure 7):

$$
d(z)=d_{0} \sqrt{\frac{z+h}{h}} \quad-h \leq z \leq 0
$$

Note that the FE discretization of the TMAZ in the global analysis uses a much coarser mesh than the one used for local analysis. This coarser resolution is the main reason to spread uniformly the power input to all the elements belonging to the control volume representing the TMAZ in the global analysis. The resulting power density is computed as:

$$
\dot{Q}=\frac{\dot{P}}{V_{T M A Z}}
$$

where $V_{T M A Z}=\left.\sum_{e=1}^{n e} V^{(e)}\right|_{e \in T M A Z}$ is the control volume representing the TMAZ in the global level analysis (see figure 8). This power re-distribution preserves the total amount of energy input independently of the mesh used ([25]).

The formulations used for global problem are summarized in table 2 (see ref. [25] and nomenclature at the end of the article). 
Table 2: Formulations used at global level

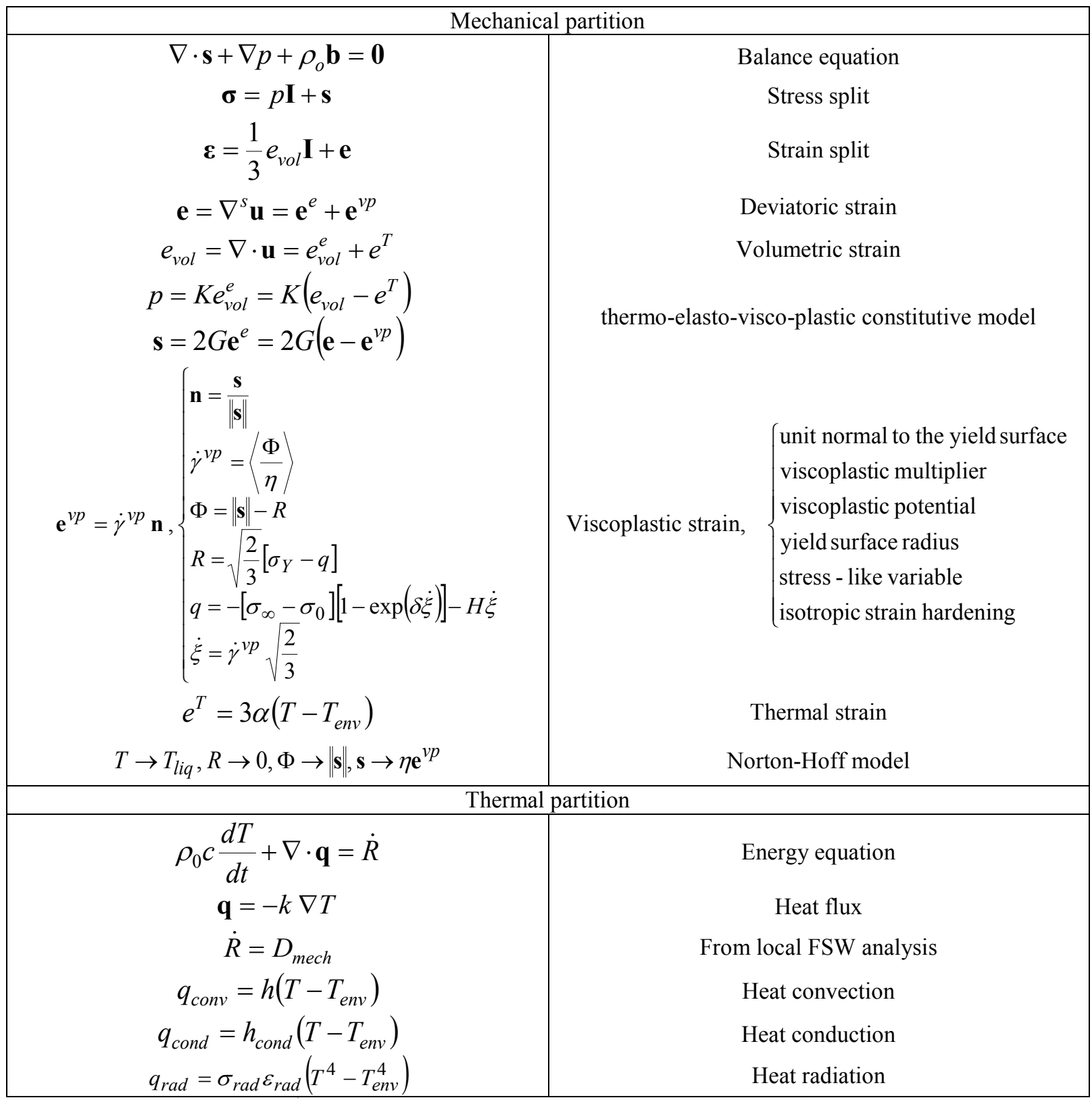

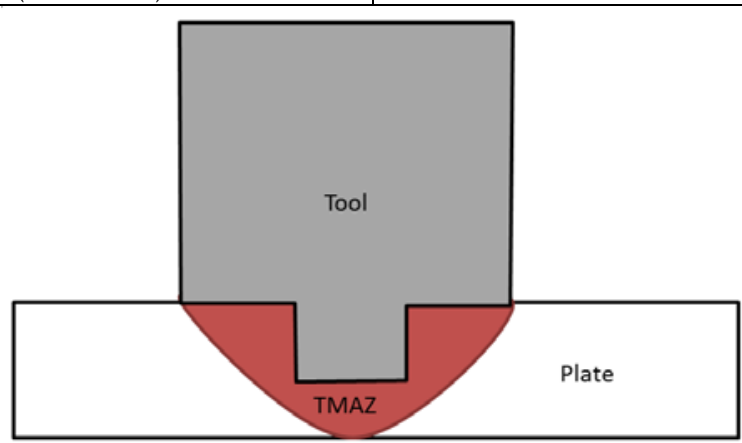

Figure 6: TMAZ at local level 


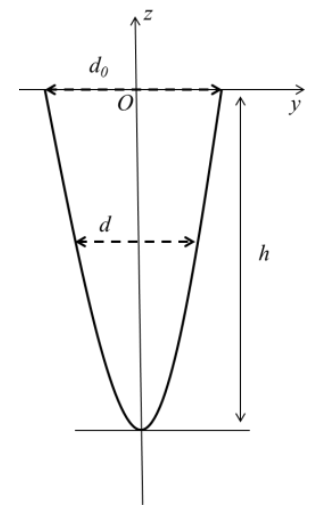

Figure 7: Schematic diagram of heat source model

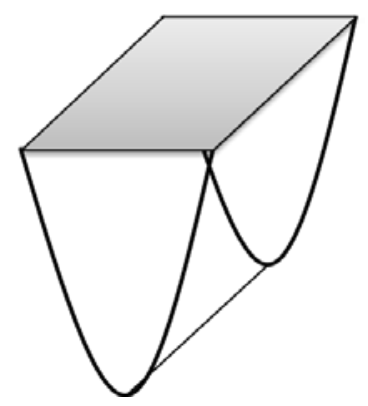

Figure 8: Heat source (represented TMAZ) at global level

\section{Experimental validation}

For the validation of the proposed strategy, geometrical data, process parameters, material properties and experimental results are taken from Zhu and Chao [16] and Agelet et al [4]. The diameters of the shoulder and pin are $19.05 \mathrm{~mm}$ and $6.35 \mathrm{~mm}$, respectively. The depth of the pin is $3 \mathrm{~mm}$. The length of the work-pieces, along the welding direction, is $300 \mathrm{~mm}$. The total width of the work-pieces is $200 \mathrm{~mm}$ and the thickness is $3.18 \mathrm{~mm}$ (see figure 9-a).

The rotational velocity and advancing velocity of the tool are $300 \mathrm{rpm}$ and $101 \mathrm{~mm} / \mathrm{min}$, respectively. Material properties are shown in figure 10 .

Convection and radiation heat transfer are considered through the top surfaces of the workpieces. The heat transfer coefficient is $10 \mathrm{~W} / \mathrm{m}^{2}{ }^{\circ} \mathrm{C}$ and the emissivity parameter is 0.17 . In order to analyze the problem at local level a smaller domain is considered. The pin and the shoulder are modeled. As the shoulder diameter is $19.05 \mathrm{~mm}$, the HAZ region is of $38.1 \mathrm{~mm}$ 
diameter and the plate is a square of $76.2 \times 76.2$ (see figure $9-b$ ). This domain is large enough so that no heat conduction needs to be considered through the lateral boundaries

At local level, the material behavior of the work-piece is modeled using a Sheppard-Wright constitutive model and the corresponding parameters are presented in table 3 .

A finite element mesh consisting of around 460,000 linear tetrahedral elements and 80,000 nodes is considered (see figure 9-b). The average element size within the HAZ is about 0.5 $\mathrm{mm}$.

The outcome of this analysis is the power energy generated by plastic dissipation and friction of $\dot{P}=1998.7 \mathrm{~W}$. This result is in good agreement with the value of $1760 \mathrm{~W}$ proposed in reference [16], computed using the torque value recorded by the FSW tool.

To solve global level analysis, a finite element mesh consisting of around 50,000 linear tetrahedral elements and 12,500 nodes is considered (see figure 11). The average element size within the TMAZ is about $3 \mathrm{~mm}$.

The temperature evolution obtained from both local and global level analyses at different lines parallel to the weld path are presented in figures 12 and 14 . The temperature is recorded at the same locations of the thermocouples during the experimental test in [16]. Four lines along the bottom surface of the work-piece are located at $y=12.7 \mathrm{~mm}, \mathrm{y}=18 \mathrm{~mm}, \mathrm{y}=21 \mathrm{~mm}$ and $\mathrm{y}=27.5$ $\mathrm{mm}$ from the welding line. The results show good agreement between the experiment and the global analysis (figure 12). Remarkable agreement is achieved for the lines at $\mathrm{y}=18 \mathrm{~mm}$ and $\mathrm{y}=21 \mathrm{~mm}$. The result for the line $\mathrm{y}=12.7 \mathrm{~mm}$ (located close to the weld line) is underestimated, probably because the global model does not reproduce the TMAZ in detail. The temperature contour fill for both local and global models is shown in figure 13. Note that the local analysis is performed in a Eulerian/ALE framework while the global level analysis is done in a Lagrangian one. To compare one against the other, the necessary transformation 
based on the advancing velocity of the pin must be performed. This comparison for points located at different distances from the weld line is shown in figure 13. The temperature field obtained from global analysis fits well with that of local analysis (figure 14). This validates the local-global approach with transfer of the computed power from the local to the global model. This result shows that both local and global models can accurately predict the temperature distribution induced by FSW process.

The global level analysis provides the residual stress field. The variations of the residual stress (normal stresses in $\mathrm{x}$ direction) along the transverse direction (orthogonal to the weld line) at $\mathrm{x}=152 \mathrm{~mm}$ are plotted in figure 15 and compared with experimental data at the same location taken from [16]. Longitudinal stresses after the cooling phase are plotted in this figure. They are compared with the test data which are measured at $\mathrm{z}=1.3 \mathrm{~mm}$ from the top surface of work-piece. The final longitudinal residual stresses are in remarkable agreement with the experimental data both in the areas under tension and under compression. The calculated residual stresses are rather small in the transverse direction, which agrees with the experimental evidence.

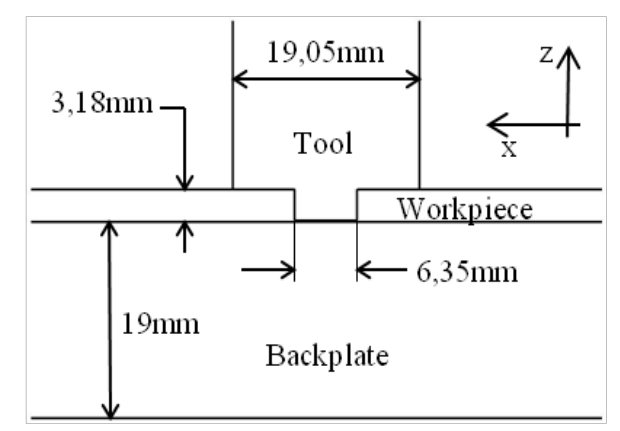

(a)

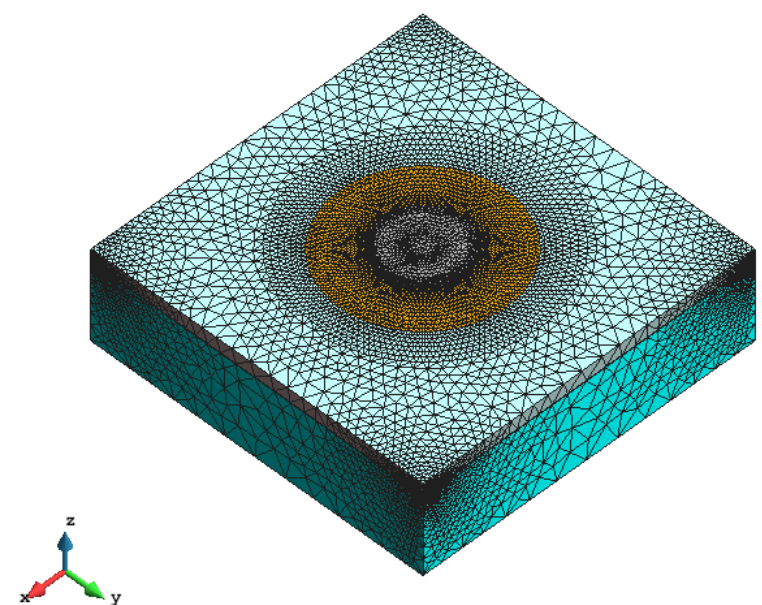

(b)

Figure 9: (a) Geometrical model (b) FE discretization (local analysis) 


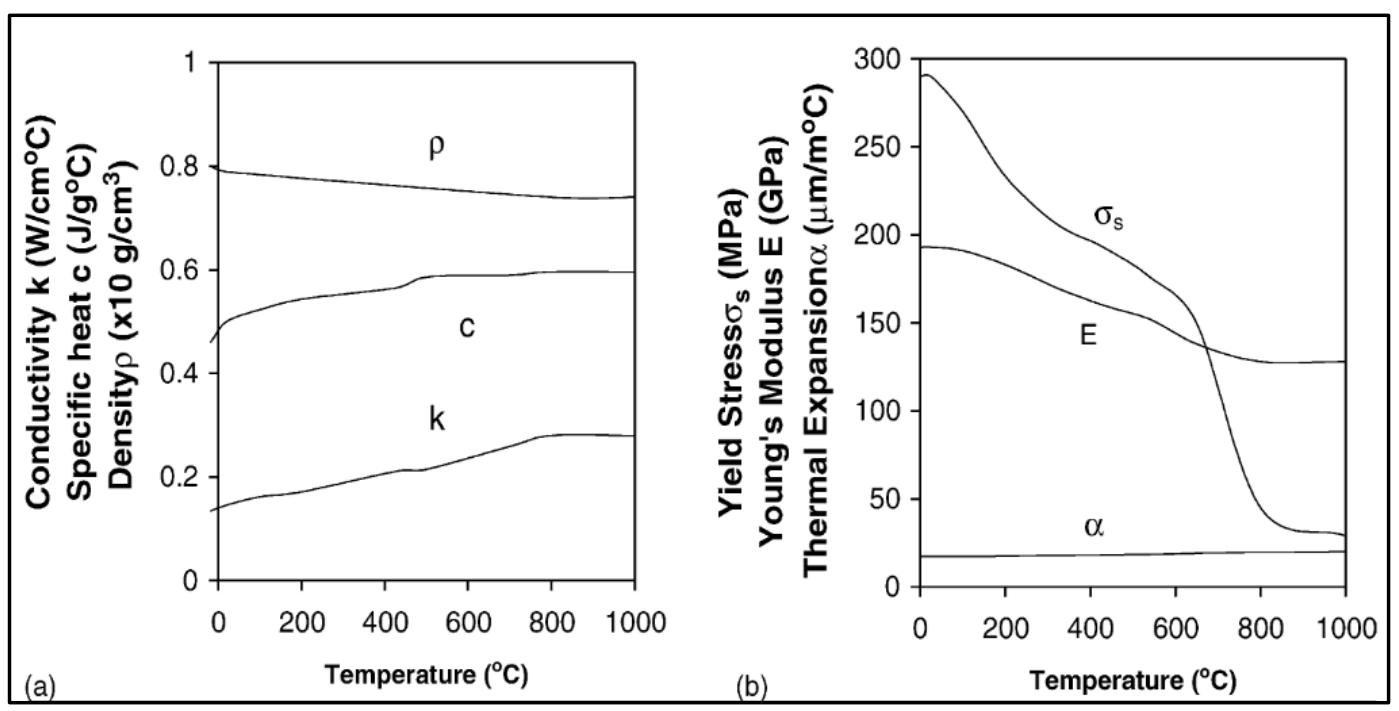

Figure 10: Material properties for the global level analysis [16]

Table 3: Material parameters for the Sheppard-Wright material model for the work-pieces

\begin{tabular}{|c|c|c|}
\hline \multicolumn{2}{|c|}{$\mu_{\text {eff }}=\frac{\frac{1}{\alpha} \sinh ^{-1}\left(\left(\frac{Z}{A}\right)^{\frac{1}{n}}\right)}{\sqrt{6}\|\dot{\mathbf{e}}\|} ; Z=\sqrt{\frac{2}{3}}\|\dot{\mathbf{e}}\| \exp \left(\frac{Q}{R T}\right)$} \\
\hline$\alpha$ & Material constant & $1.2 \mathrm{E}-08 \mathrm{~Pa}^{-1}$ \\
\hline$A$ & Material constant & $8.3 \mathrm{E}+15$ \\
\hline$n$ & Material constant & 4.32 \\
\hline$R$ & Universal gas constant & $8.314(\mathrm{~J} / \mathrm{K} \mathrm{mol})$ \\
\hline$Q$ & Activation energy & $4.01 \mathrm{E}+05 \mathrm{~J} \mathrm{~mol}^{-1}$ \\
\hline
\end{tabular}




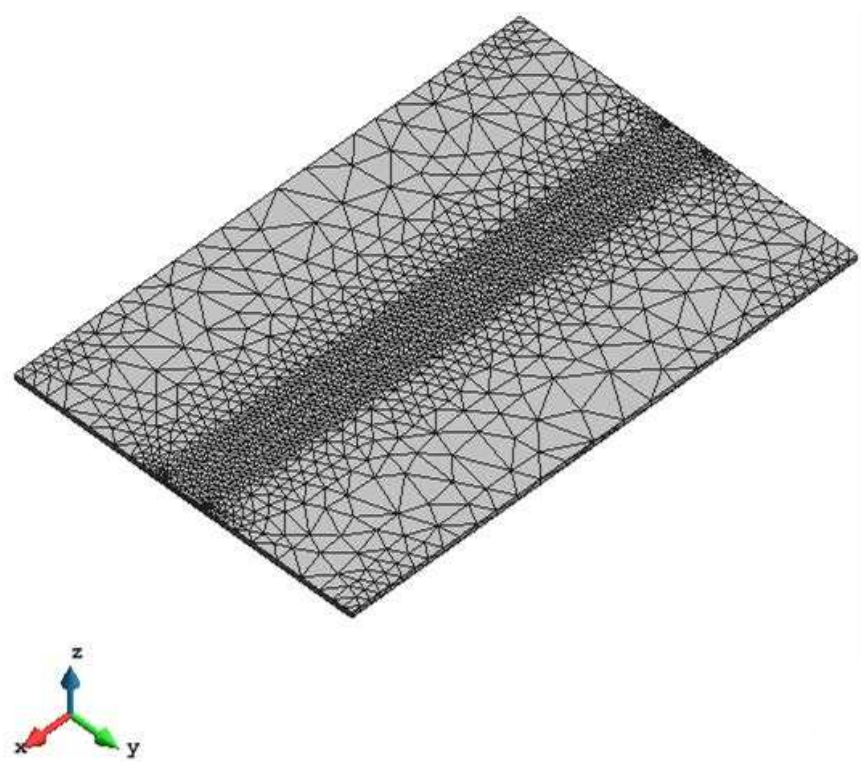

Figure 11: FE discretization (global analysis)

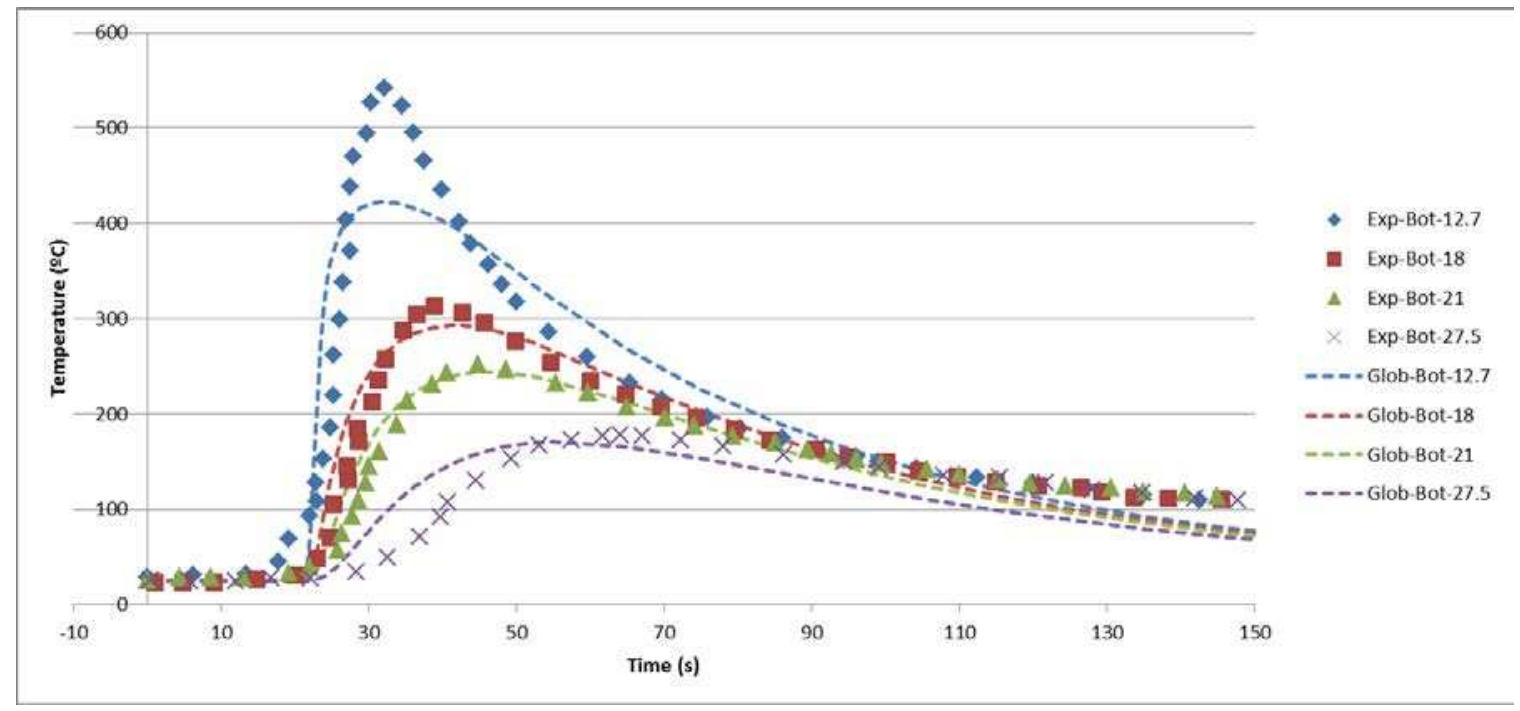

Figure 12: Temperature evolution obtained from global level analysis compared with experiment 


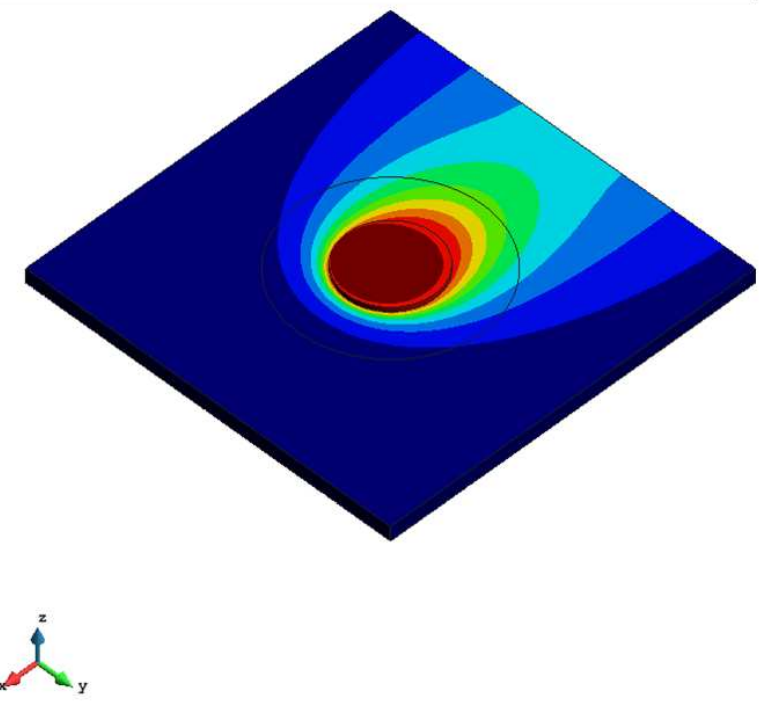

(a)
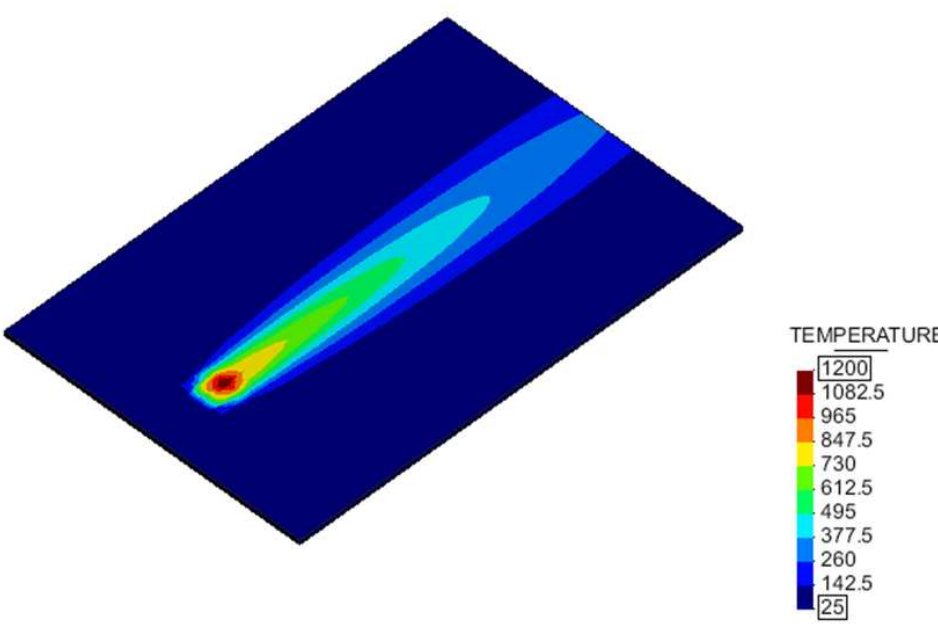

GiD

Figure 13: Temperature field at (a) local level (b) global level

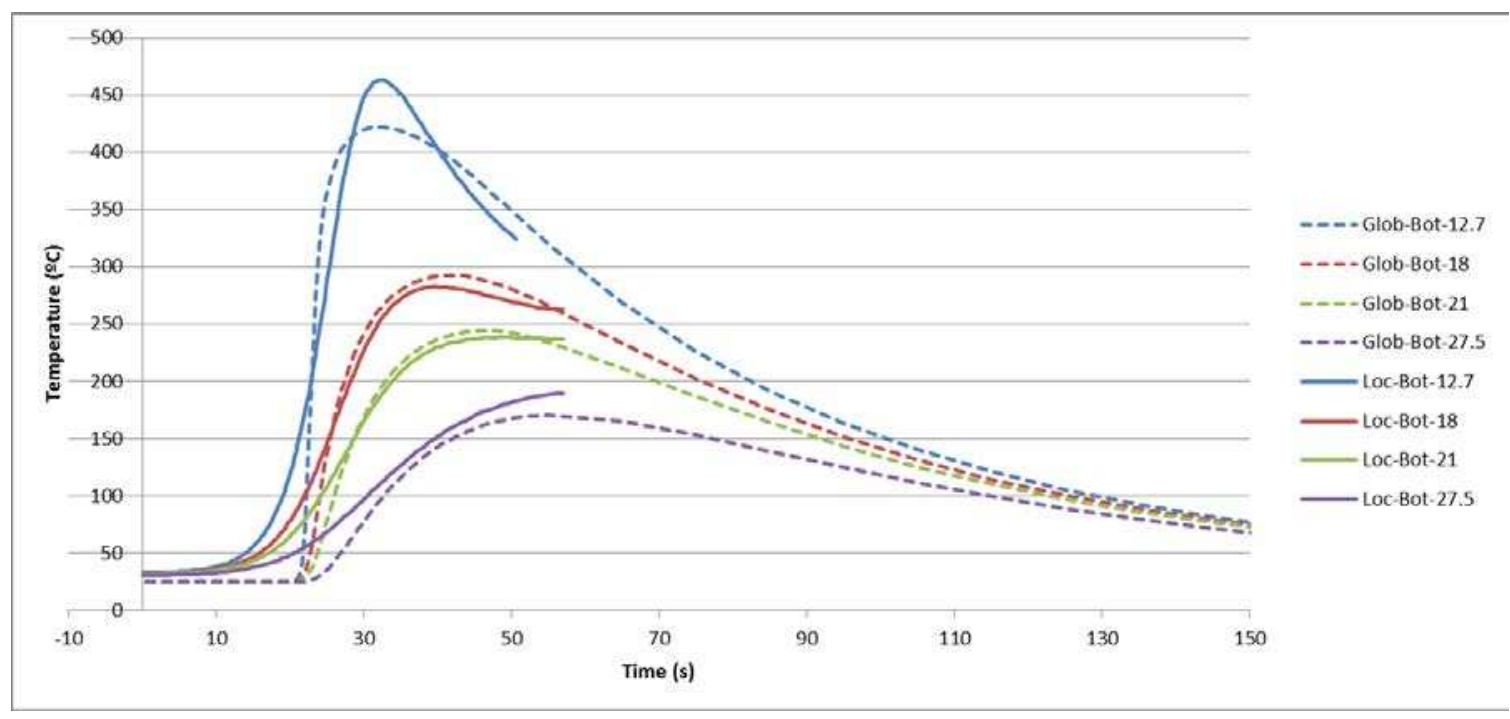

(b)

Figure 14: Temperature evolution obtained from global level analysis compared with local level analysis 


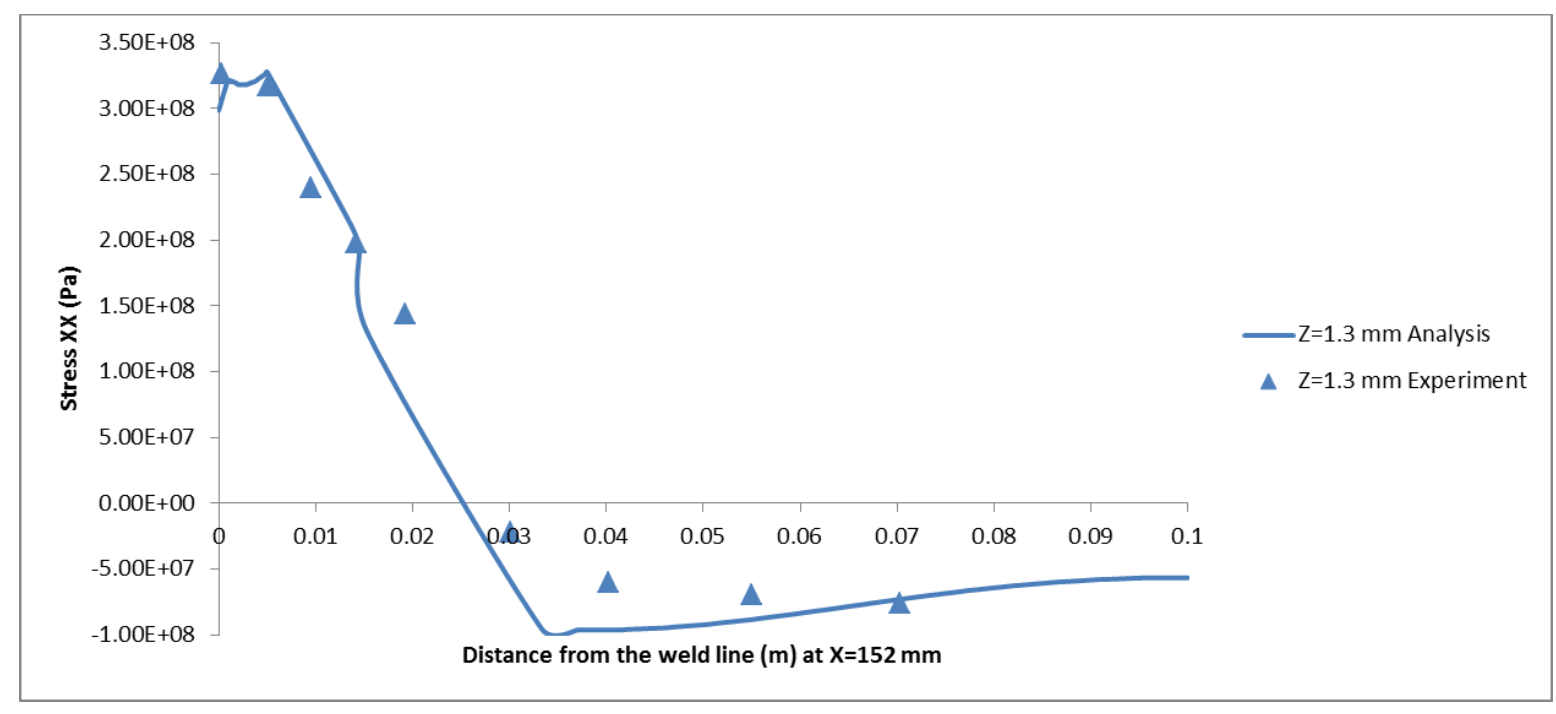

Figure 15: Comparison between the stresses obtained from global level analysis and experimental data at a line orthogonal to the weld line

\section{Conclusion}

This work proposes a local-global two level strategy for the prediction of residual stresses in FSW processes.

In a first step, the local level analysis is performed in order to calculate the power input for the global level simulation. The local model takes into account the interaction between the tool and the workpiece getting a description of the process closer to reality. The transient coupled thermo-mechanical local analysis is performed once until the steady-state is reached. In this configuration, the power heat input is computed to be used as an input in the global level analysis. The total heat power is computed summing both viscous dissipation and friction. This is the only data transferred between local and global model.

In a second step, the transient coupled thermo-mechanical global analysis is performed. In the global level analysis the overall structural response is found. Using the total heat power computed in the local simulation, the residual stress in the friction stir welded plate is then 
obtained. In this way, the proposed approach allows for getting residual stresses field closer to reality and it is energy conserving.

The proposed strategy has been validated with experimental data. The local and global problems are defined, in terms of geometry, boundary conditions and material property. The temperature fields obtained from both local and global analyses as well as the residual stresses at global simulation are examined and compared with experimental verification.

The obtained results are in remarkable agreement with the available experimental evidence both in terms of peak and distribution of temperature and, more relevantly, quantitative and qualitative distribution of residual stresses. 


\section{Acknowledgment}

Financial support from the EC 7th Framework Programme and the Spanish Ministry of Economy and Competitivity under the EACY project (EACY: Ref. MAT2013-48624-C2-1-P)

- Enhanced accuracy computational and experimental framework for strain localization and failure mechanisms - within the "Excellency" Programme for Knowledge Generation are gratefully acknowledged.

\section{Nomenclature}

\begin{tabular}{|ll|}
\hline $\mathbf{s}$ & Stress deviator \\
$p$ & Pressure \\
$\rho_{0}$ & density in the reference configuration \\
$\mathbf{b}$ & body forces vector per unit of volume \\
$\mathbf{v}$ & Velocity field \\
$\mathbf{\sigma}$ & Cauchy's stress tensor \\
$\dot{\boldsymbol{\varepsilon}}$ & Strain rate \\
$\mu_{\text {eff }}$ & Effective viscosity \\
$c$ & Specific heat \\
$T$ & Temperature \\
$\mathbf{v}_{\text {mesh }}$ & Velocity of the mesh \\
$k$ & Thermal conductivity \\
$\beta$ & Fraction of plastic dissipation \\
$h$ & Heat transfer coefficient by convection \\
$h_{\text {cond }}$ & Heat transfer coefficient by conduction \\
$\sigma_{\text {rad }}$ & Stefan-Boltzmann constant \\
$\varepsilon_{\text {rad }}$ & Emissivity factor \\
$\mathbf{e}^{e}$ & Deviatoric elastic strain \\
$e^{T}$ & Volumetric thermal strain \\
$e_{v o l}^{e}$ & Volumetric elastic strain \\
$\delta$ & Saturation exponent \\
$\eta$ & Plastic viscosity \\
$\sigma_{Y}$ & Yield stress \\
$\sigma_{\infty}$ & Saturation flow stress \\
$\sigma_{0}$ & Initial flow stress \\
$H$ & Linear hardening coefficient \\
$\alpha$ & Thermal expansion coefficient \\
$T_{e n v}$ & Environmental temperature \\
$T_{\text {liq }}$ & Liquidus temperature \\
\hline & \\
\hline
\end{tabular}




\section{References}

[1] Agelet de Saracibar, C., Chiumenti, M., Santiago, D., Dialami, N. and Lombera, G. (2010) On the numerical modeling of fsw processes. In Proceedings of the International Symposium on Plasticity and its Current Applications, Plasticity 2010, St. Kitts, St. Kitts and Nevis, January $3-8$.

[2] Agelet de Saracibar, C., Chiumenti, M., Santiago, D., Cervera, M., Dialami, N. and Lombera, G. (2010) A computational model for the numerical simulation of fsw processes. In Proceedings of the 10th International Conference on Numerical Methods in Industrial Forming Processes 1252: 81-88, Pohang, South Korea, June 13-17. AIP Conference Proceedings. doi: 10.1063/1.3457640.

[3] Agelet de Saracibar, C., Chiumenti, M., Santiago, D., Cervera, M., Dialami, N. and Lombera, G. (2011) Advances in the numerical simulation of 3D FSW processes. In Proceedings of the International Symposium on Plasticity and its Current Applications, Plasticity 2011, Puerto Vallarta, Mexico, January 3 - 8.

[4] Agelet de Saracibar, C., Chiumenti, M., Cervera, M., Dialami, N. and Seret, A. (2014) Computational modeling and sub-grid scale stabilization of incompressibility and convection in the numerical simulation of friction stir welding processes. Archives of Computational Methods in Engineering, 21(1): 3-37.

[5] Chiumenti, M., Cervera, M., Agelet de Saracibar, C. and Dialami, N. (2012) Numerical modeling of friction stir welding processes. Computer Methods in Applied Mechanics and Engineering, 254:353-369.

[6] Dialami, N., Chiumenti, M., Cervera, M. and Agelet de Saracibar, C. (2013) An apropos kinematic framework for the numerical modeling of friction stir welding. Computers and Structures 117:48-57. 
[7] Dialami N., Chiumenti M., Cervera M., Agelet de Saracibar C. and Ponthot J.-P. (2013) Material Flow Visualization in Friction Stir Welding via Particle Tracing, International Journal of Metal Forming, 1-15, DOI:10.1007/s12289-013-1157-4.

[8] Dialami N., Chiumenti M., Cervera M., Agelet de Saracibar C., Ponthot J.-P. and Bussetta Ph. (2014) Numerical simulation and visualization of material flow in Friction Stir Welding via Particle Tracing, Numerical Simulations of Coupled Problems in Engineering, Springer International Publishing, 157-169.

[9] Chiumenti, M., Cervera, M., Agelet de Saracibar, C. and Dialami, N. (2013) A novel stress accurate FE technology for highly non-linear analysis with incompressibility constraint. application to the numerical simulation of the FSW process. In Proceedings of the International Conference on Numerical Methods in Forming Processes, NUMIFORM, Shenyang, China. AIP Conference Proceedings.

[10] Bussetta P., Dialami N., Boman R., Chiumenti M., Agelet de Saracibar C., Cervera M. and Ponthot J.-P. (2014) Comparison of a fluid and a solid approach for the numerical simulation of Friction Stir Welding with a non-cylindrical pin, Steel research international, Steel research international, 85(6): 968-979.

[11] Bussetta P., Dialami N., Chiumenti M., Agelet de Saracibar C., Cervera M., Boman R. and Ponthot J.-P. (2015) 3D numerical models using a fluid or a solid formulation of FSW processes with a non-cylindrical pin, Adv.Model. and Simul. in Eng. Sci. DOI $10.1186 / \mathrm{s} 40323-015-0048-2$

[12] Chiumenti, M., de Saracibar, C.A., Cervera, M. (2008) On the Numerical modeling of the thermomechanical contact for metal casting analysis, Journal of Heat Transfer, 130 (6), 061301-061301-10. 
[13] Agelet de Saracibar C., Chiumenti M., Cervera M. (2006) Current developments on the coupled thermomechanical computational modeling of metal casting processes, Int. J. on Comp. Methods in Material Science 6:1-2.

[14] Chiumenti M., Cervera M., Dialami N., Wu B., Li J. and Agelet de Saracibar. C. (2015) Numerical modeling of the electron beam welding and its experimental validation, Submitted to Finite Elements in Analysis and Design.

[15] Buffa G., Ducato A. and Fratini L. (2011) Numerical procedure for residual stresses prediction in friction stir welding, Finite elements in analysis and design, 47: 470-476.

[16] Zhu XK, Chao YJ (2004) Numerical simulation of transient temperature and residual stresses in friction stir welding of 304L stainless steel. J Mater Process Technol. $146(2): 263-272$

[17] Khandkar MZH, Khan JA, Reynolds AP, Sutton MA. (2006) Predicting residual thermal stresses in friction stir welded metals. J Mater Process Technol, 174:195-203.

[18] Bastier A, Maitournam MH, Roger F, Dang Van K. (2008) Modelling of the residual state of friction stir welded plates. J Mater Process Technol;200:25-37

[19] Dang Van, K., Maitournam, M.H., (1993) Steady-state flow in classical elastoplasticity: applications to repeated rolling and sliding contact. J. Mech. Phys. Solids, 1691-1710

[20] McCune RW, Murphy A, Price M, Butterfield J. (2012) The influence of friction stir welding process idealization on residual stress and distortion predictions for future airframe assembly simulations. J. Manuf. Sci. Eng. 134(3): 031011-031011-9.

[21] Paulo RMF, Carlone P, Valente RAF, Teixeira-Dias F, Palazzo GS. (2013) Integrated design and numerical simulation of stiffened panels including friction stir welding effects. Key Eng. Mater. 554-557:2237-42. 
[22] Yan DY, Wu AP, Silvanus J, Shi QY. (2011) Predicting residual distortion of aluminum alloy stiffened sheet after friction stir welding by numerical simulation. Materials \& Design, 32(4):2284-2291.

[23] Fratini L, Pasta S. (2012) Residual stresses in friction stir welded parts of complex geometry. Int J Adv Manuf Technol, 59:547-557.

[24] Rahmati Darvazi A., Iranmanesh M. (2014) Prediction of asymmetric transient temperature and longitudinal . residual stress in friction stir welding of 304L stainless steel, Materials \& Design, 55:812-820.

[25] Chiumenti M., Cervera M., Salmi A., Agelet de Saracibar C., Dialami N., Matsui K. (2010) Finite element modeling of multi-pass welding and shaped metal deposition processes. Comput Method Appl Mech Eng, 199:2343-2359.

[26] Shi Q.-Y., Dickerson T. and Shercliff H. R. (2003) thermomechanical FE modelling of friction stir welding of Al-2024 including tool loads, 4th International Symposium on Friction Stir Welding (Park City, UT), TWI, Cambridge.

[27] Dureisseix D. and Bavestrello H. (2006) Information transfer between incompatible finite element meshes: Application to coupled thermo-viscoelasticity. Comput. Methods Appl. Mech. Engrg., 195:6523-6541.

[28] Farrell P.E., Piggott M.D., Pain C.C., Gorman G.J., and Wilson C.R. (2009) Conservative interpolation between unstructured meshes via supermesh construction. Comput. Methods Appl. Mech. Engrg., 198:2632-2642. 